\title{
Community food production as food security: Resource and market valuation in Madison, Wisconsin (USA)
}

\author{
Vincent M. Smith ${ }^{\text {a* }}$ \\ Southern Oregon University \\ John A. Harrington ${ }^{\text {b }}$ \\ University of Wisconsin-Madison
}

\begin{abstract}
Submitted July 22, 2013 / Revised October 11 and November 26, 2013 / Accepted November 26, 2013 /
Published online March 10, 2014

Citation: Smith, V. M., \& Harrington, J. A. (2014). Community food production as food security: Resource and

market valuation in Madison, Wisconsin (USA). Journal of Agriculture, Food Systems, and Community Development,

4(2), 61-80. http://dx.doi.org/10.5304/jafscd.2014.042.006

Copyright (C) 2014 by New Leaf Associates, Inc.
\end{abstract}

\begin{abstract}
Community food production (CFP) is emerging worldwide as a key component of programming designed to address community food insecurity. CFP resources in the form of home gardens, community gardens, and school gardens continue to gain wide support and attention. However, the market value of gardening and garden-based programs as well as how this market value correlates to food-insecure communities are not yet well understood.

This research explores, defines, and maps this value in the Madison, Wisconsin, Urban Area

\footnotetext{
a* Corresponding author: Vincent M. Smith, Departments of Environmental Studies and Sociology, Southern Oregon University, 1250 Siskiyou Boulevard, Ashland, Oregon 97520 USA; +1-541-552-6802; smithv3@,sou.edu

${ }^{b}$ Department of Landscape Architecture, University of Wisconsin-Madison, 1450 Linden Drive, Madison, Wisconsin 53706 USA; jaharrin@,wisc.edu
}

(USA). The extent of CFP, including both the total number of gardens and their overall area within the study, was measured and mapped through the use of a random sidewalk and roadside survey of 2,454 addresses and existing lists of area community and school gardens. The productive output of these gardens in terms of weight, gross and net market value, and caloric value was determined through test plots $(\mathrm{n}=36)$ tended by citizen scientists and used to estimate the absolute and relative contribution of CFP for the Madison Urban Area in terms of market value and caloric value. The work concludes with a discussion of the current and future role of CFP as a component of community food security efforts and the need to carefully assess intended objectives and attributed values.

\section{Keywords}

community food production, community food security, community gardening, home gardening, urban agriculture 


\section{Introduction and Literature Review}

Urban and peri-urban agriculture (UPA) has expanded both nationally and internationally over the past two decades (Bellows, Brown, \& Smit, 2003; Bruinsma \& Hertog, 2003; Patel \& MacRae, 2012). The United Nations Food and Agriculture Organization (FAO) reports that 70 percent of the world's urban population participates in urban agriculture in some form (FAO, 2010, p. 1); this produces 15 to 30 percent of the world's food supply (Johnson, 2013).

In the U.S. context, urban farming, community gardening, home gardening, and food share systems - all forms of UPA, if broadly defined are frequently of interest not only because of where (Mougeot, 2000) they are practiced but why (Smith, 2011) they are practiced. The United States Department of Agriculture (USDA) refers to the practice of individuals and communities growing their own food as community food production (CFP), a term defined more explicitly elsewhere (Smith, 2011, p. 9) as "the act of growing food within a community, for that community, and by that community."

CFP takes place in both urban and rural environments and can be recognized by its specific emphasis on consumers participating in the act of production. Our research focuses exclusively on home gardening, community gardening, and school gardening within the Madison Urban Area (MUA). The phrase "community food production" is used throughout this paper to emphasize the forms of agriculture in which consumers actively participate in production. In the case of the MUA this emphasis excluded at least one large urban farm. Our focus is not intended to underemphasize the importance of urban farming, but to explore more fully the specific impact of gardening as a form of community food security.

The growth of CFP on the American landscape in the form of community gardens, home gardens, and school gardens has not gone unnoticed. Several municipalities across the United States have responded to the growth of CFP by adopting planning or zoning documents to facilitate or control its growth and placement (Mannion, 2009; Mendes, Balmer, Kaethler, \& Rhoads, 2008; Mukherji \& Morales, 2010).

As resources are consumed to plan for and to establish CFP, it becomes increasingly important to understand its role on the community. The value of CFP, or its potential lack of value, must be considered in a wide range of contexts. First, land use change, especially in urban and peri-urban environments, has the potential to impact and be impacted by a wide range of ecological systems, including air quality, water quality, stormwater runoff, solid waste streams, soil toxicity, urban water use, and wildlife habitat. Second, CFP is thought to have a wide range of sociological values for participants, including food security, workforce training, community enhancement, and economic development (Blair, Giesecke, \& Sherman, 1991; Draper \& Freedman, 2010; Ojo, 2009). These values vary widely and are just beginning to be understood (Lawson, 2005).

Community food security advocates have consistently raised the idea of CFP as a component of community food security (Bruinsma \& Hertog, 2003; Meenar \& Hoover, 2012). We define community food security as a condition in which all community residents obtain a safe, culturally acceptable, nutritionally adequate diet through a sustainable food system that maximizes community self-reliance, social justice, and democratic decision-making (Hamm \& Bellows, 2003). Emergency food providers, such as food pantries, are now planting their own gardens to secure fresh food, and many organizations and programs now exist for home gardeners and community gardeners to donate to food pantries or community kitchens. Community gardening has been at the forefront of CFP programs designed to impact food security. Community gardening organizations frequently identify food security as an objective and suggest that their gardens provide needed healthy fresh fruits and vegetables to food-insecure populations.

Whether community gardens actually serve food-insecure populations and whether the financial investment in community gardening is outweighed by its financial benefits are important considerations. For example, while CFP is often thought to benefit low-income families through its dollar value contribution, others have demonstrated that it is not a lack of money, but rather a lack of time, that serves as a barrier to fresh food for low-income households (Davis \& You, 2011). 
Still others have shown that community food programs such as community gardens are actually highly underutilized by the food-insecure populations they were designed to serve (Kirkpatrick \& Tarasuk, 2009; Meenar \& Hoover, 2012). Urban agriculture in its many forms remains highly contested as a component of food security infrastructure (Hallsworth \& Wong, 2013; Weissman, 2013) at least in part due to the difficulty of assessing its market value.

The growth in CFP is thought to be a direct response to inadequate or unreliable access to food and a lack of purchasing power (Bruinsma \& Hertog, 2003). In addition, international CFP development is expected to continue as the world population of urban dwellers and the population of urban poor continue to climb (Bruinsma \& Hertog, 2003). The severe lack of food access has even led some to report that CFP is a "necessity" in urban areas of the global south (Eriksen-Hamel \& Danso, 2010). The international push for urban agriculture or CFP is not surprising. Even in regions with short growing seasons and harsh climates, such as Nepal, CFP can meet 60 percent of a family's total fruit and vegetable needs (Gautam, Suwal, \& Sthapit, 2009). Rooftop gardening, a specific manifestation of CFP, also has shown tremendous promise as a source of food security (Khandaker, 2004).

The value of CFP as a component of community food security is not restricted to the developing world, however. The USDA has published a standardized tool for community food security assessment that includes an assessment of "community food production resources" (Cohen, 2002). Interestingly, this assessment is based entirely on whether CFP resources exist rather than any assessment of agricultural production or distribution.

Advocates for CFP within the community food security community have asserted that anyone able to grow their own food or at least some portion of that food will save themselves the cost of purchasing that which has been grown (Brown, Bailkey, Meares-Cohen, Nasr, Smit, \& Buchanan, 2002). In 2011 Americans were spending 9.8 percent of their disposable income on food (USDA, 2012); therefore a reduction in household food expenditures may substantially affect household disposable income.

The cost of one's time is frequently not considered in these arguments (Brown et al., 2002). For most home and community gardeners, labor costs are of minimal importance, but if gardening is to be viewed as having production value in its own right, these costs are of great importance. A gardener's time, however, is difficult to translate into a dollar figure. The assumption is clearly that the productive potential of CFP is a form of food security, but the question is more complex and involves a question of garden expenses, time spent gardening, or in short, an understanding of the production value of CFP.

If CFP is to be promoted as a community food security tool, a careful study of its agricultural and market contribution is important. Anecdotal reports that a single community garden produces over 50,000 pounds $(22,680 \mathrm{~kg})$ of food appears impressive, but perhaps not as impressive if that production represents only 1 percent of the total food needs of the growers in that garden. Careful exploration of the values attributed to CFP is clearly important. In discussing this need, Laura Lawson noted,

The many outcomes associated with gardens have also attracted support from various organizations, including beautification groups, charitable organizations, government agencies, environmental groups, and neighborhood associations. The up side of this fact is that it allows programs to draw on many interests and resources. The down side is that the high ideals associated with gardens rarely can be documented or verified. (Lawson, 2005, p. 11)

\section{Applied Research Methods}

\section{Site Selection}

This research explores the potential value of CFP as a tool to combat community food insecurity in the MUA. Madison was chosen for this study for several reasons. With its rich agricultural history and substantial planning for community gardens, Madison is an appropriate location for a study of CFP. The urban area, located within Dane County, 
is home to more than 40 organizations devoted to community food system design, boasts more than 60 community gardens, hosts the largest produceronly farmers' market in the United States, and contains more home gardens than would be reasonable for a person to count. The widespread investment in CFP and several nonprofit organizations' desires to assess and evaluate the value of that investment make the Madison area an ideal candidate for investigation.

According to the U.S.

Census Bureau's definition of an Urban Area, the MUA consists of contiguous, densely settled census block groups and census blocks of at least 1,000 people per square mile, along with adjacent census blocks of at least 500 people per square mile that together encompass a population of at least 50,000 people (U.S. Census Bureau, 2012).

While the city of Madison composes a large portion of this urban area, it does not exclusively represent the urban area. Neighboring cities have developed alongside Madison, creating a single extensive urban area comprising 119 square miles (309 square $\mathrm{km}$ ) of largely mixed residential land use. Figure 1 shows the study area in the context of the Upper Midwest region. Using Urban Area as a study boundary emphasizes inclusion of land use that is not primarily agriculture, but which has the potential to include agriculture in some form and on some scale as a complementary land use feature. Several other options existed for delineation of our study area, including metropolitan statistical area, urban planning area, and regional commuter network analysis. Our choice to use urban area was based our need to limit travel time and expense for survey teams as well as the need to have the area line up with census tract data. The use of a larger study area such as metropolitan statistical area would also
Figure 1. The Madison Urban Area (MUA) in the Context of the Great Lakes Region and the Yahara Lakes Chain (shown in black)

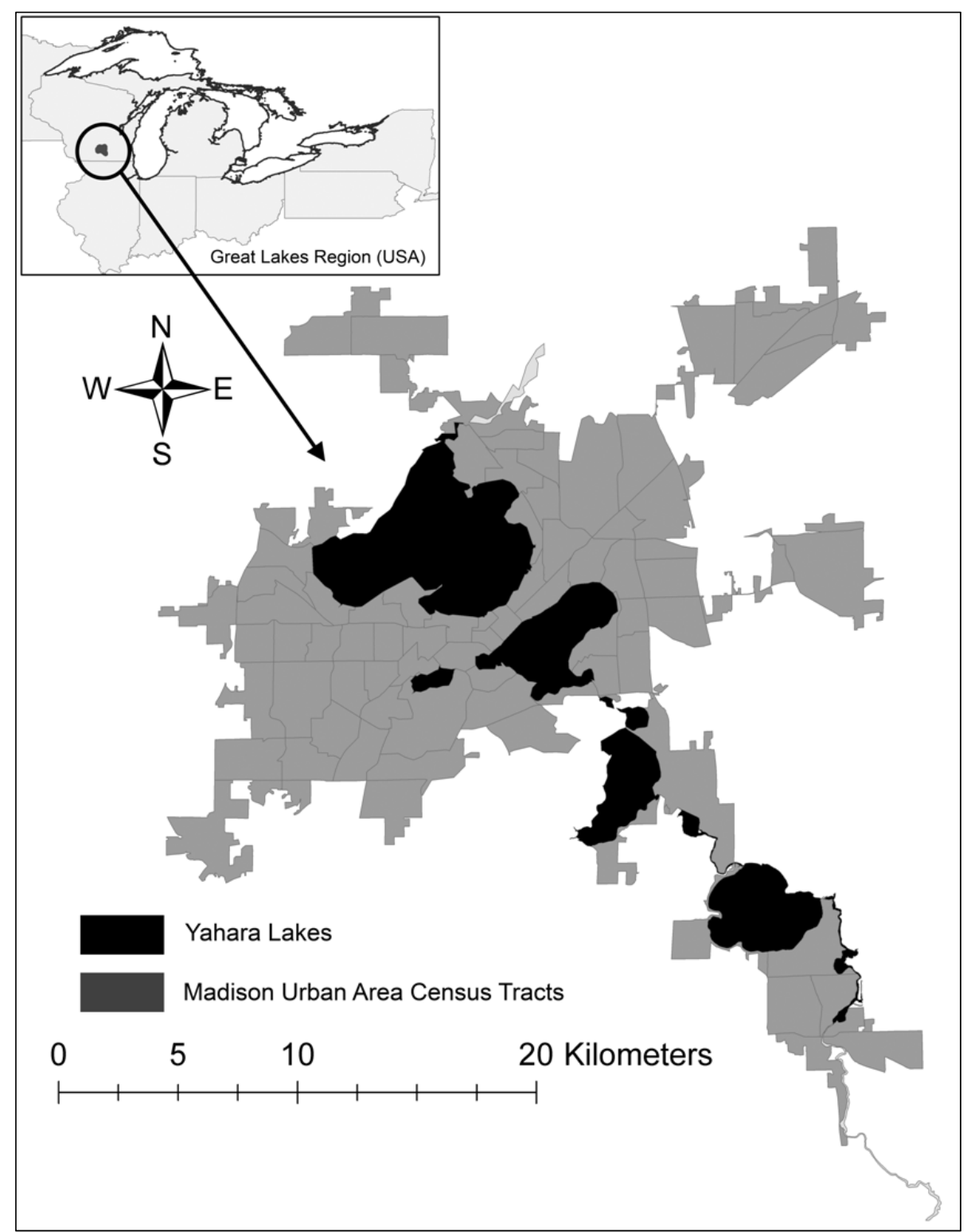


have been of interest, but would have required additional time.

The MUA contains part or all of 87 census tracts, or 5,019 total census blocks, comprising a total population of 346,496 individuals or 158,313 households as listed in the 2009 American Community Survey five-year estimates (U.S. Census Bureau, 2009). The estimated median household income across the entire MUA was US\$54,057 in 2009. However, median household income broken down by tract was available only from the 2000

Figure 2. 1999 Madison Urban Area (MUA) Median Household Income Median household income of the MUA tends to increase as distance from urban center increases.

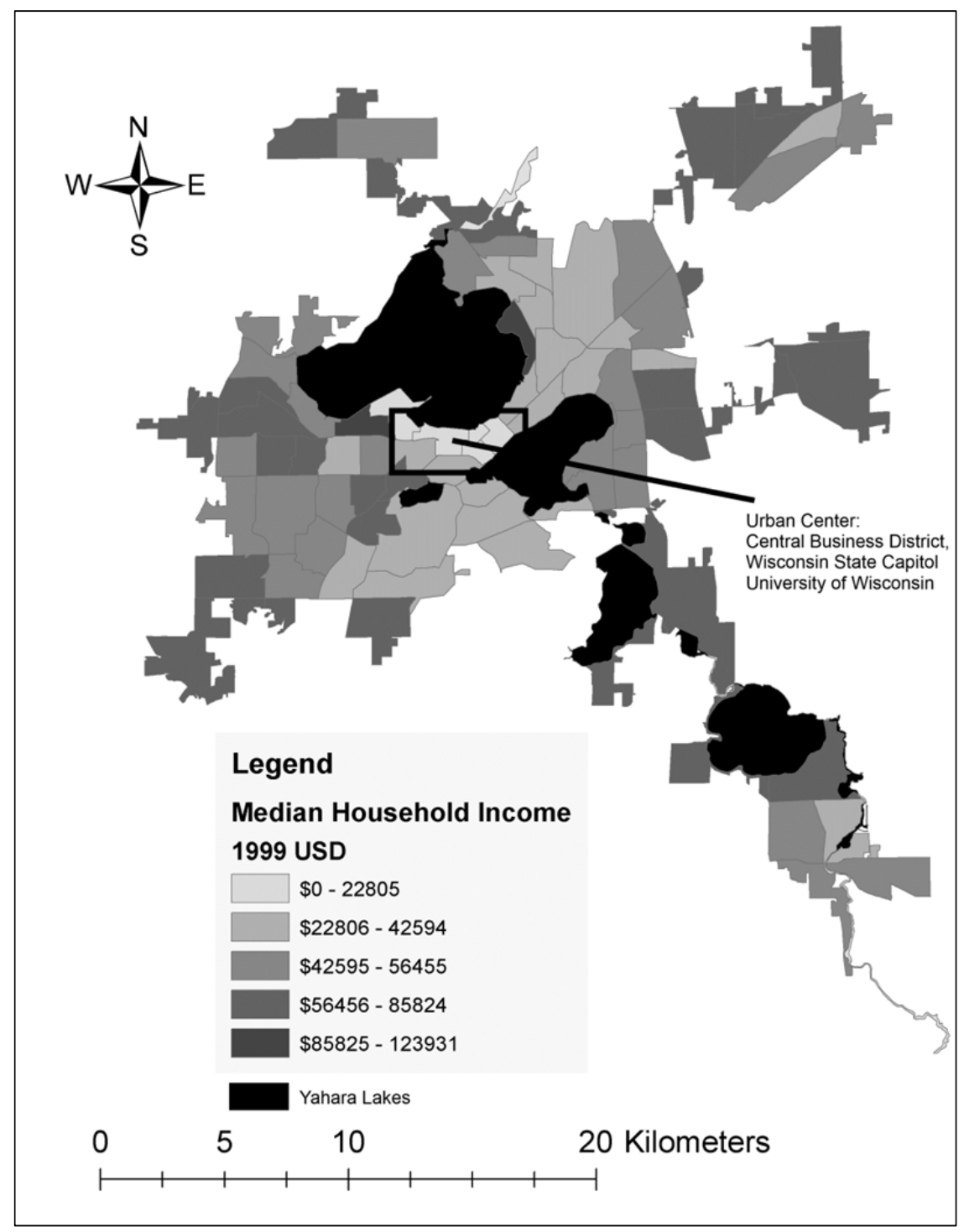

decennial census, which reflects 1999 income levels. In 1999 the median household income of the MUA as a whole was US $\$ 45,952$. The median household income of census tracts ranged from US $\$ 10,258$ to US $\$ 123,931$, with quartile breaks at US $\$ 37,388$, US $\$ 50,699$, and US\$61,912. Not unlike many U.S. cities, median household income was generally highest along the urban fringe where home and lot size are larger as shown in figure 2. Low median household income near the city center is likely correlated with the large number of University of Wisconsin-Madison students who live in this area.

\section{Spatial Configuration}

Where CFP occurs within a community may influence its effectiveness as a form of community food security, who benefits from its potential value, and the trends in what may be motivating or limiting its practice. We captured the spatial composition and configuration of CFP in a geodatabase and analyzed them against tractlevel median household income, percent of homes owned versus rented, and percentage of single-family residences (drawn from the 2000 U.S. Census).

Mapping home gardens within the MUA has never been attempted, but as we began this study we estimated that the total number of home gardens in the MUA alone to be in the tens of thousands. We found the high-resolution orthophotos to be highly unreliable for identifying home food production. We therefore developed a novel process to determine home food garden presence and size. This pro- 
cess included conducting a field survey of CFP gardens. Surveyors walked around neighborhoods and observed the presence of gardens in both front and back yards. Because this is a labor-intensive process and the MUA is quite large, we chose a subset of tracts.

We chose census tract as an aggregate because of the rich data set available. In addition, the number of census tracts within the area was a manageable size for investigation. We first assigned the 87 census tracts within the MUA to one of four household median income levels based on quartiles taken from the 2000 U.S. decennial census. We then randomly selected four tracts from each of these quartiles using a "sample" command in the statistical software program, "R." The resulting sample of 16 of 87 census tracts is shown in figure 3. We then used " $R$ " to randomly select eight blocks within each tract. The order of blocks selected was retained as it was unknown whether time would permit a sample of all eight blocks from each of the 16 tracts. Any reduction in blocks being sampled would follow the order in which blocks were randomly selected in R.

Beginning in June 2010, we trained nine undergraduate researchers to identify food crops. Survey teams composed of three individuals recorded the presence or absence of food production at each address and parcel within the selected block by visual identification while surveying from sidewalks and roadsides. Teams did not go onto private property at any time. Teams were assisted by parcel and road maps of all surveyed blocks. The research group traveled together as one single unit for the first month of surveying to insure that plant identification skills were solid and data were entered consistently. The flat and open terrain within the MUA made identification of areas of food production possible. Of the more than 2,000 addresses visited, we were able to gain a full view of the parcel in every case. In the event that a single parcel contained more than one address, as was frequently the case for parcels with multifamily structures, each address was individually surveyed. In addition to garden presence or absence, survey teams identified the land use of the parcel grouped as singlefamily residence, multifamily residence, commercial, industrial, park, government, farm, or undeveloped land. Survey teams also identified the type of food production as either a dedicated food garden, food production integrated into ornamental landscape, or a container garden. Teams further estimated the total area of food production in square feet. We included fruit trees in our survey by
Figure 3. Madison Urban Area (MUA) Garden Sampling Design

A mulitistage random stratified probability sample was used to select census tracts (dark grey) and then blocks within those tracts (black) for analysis.

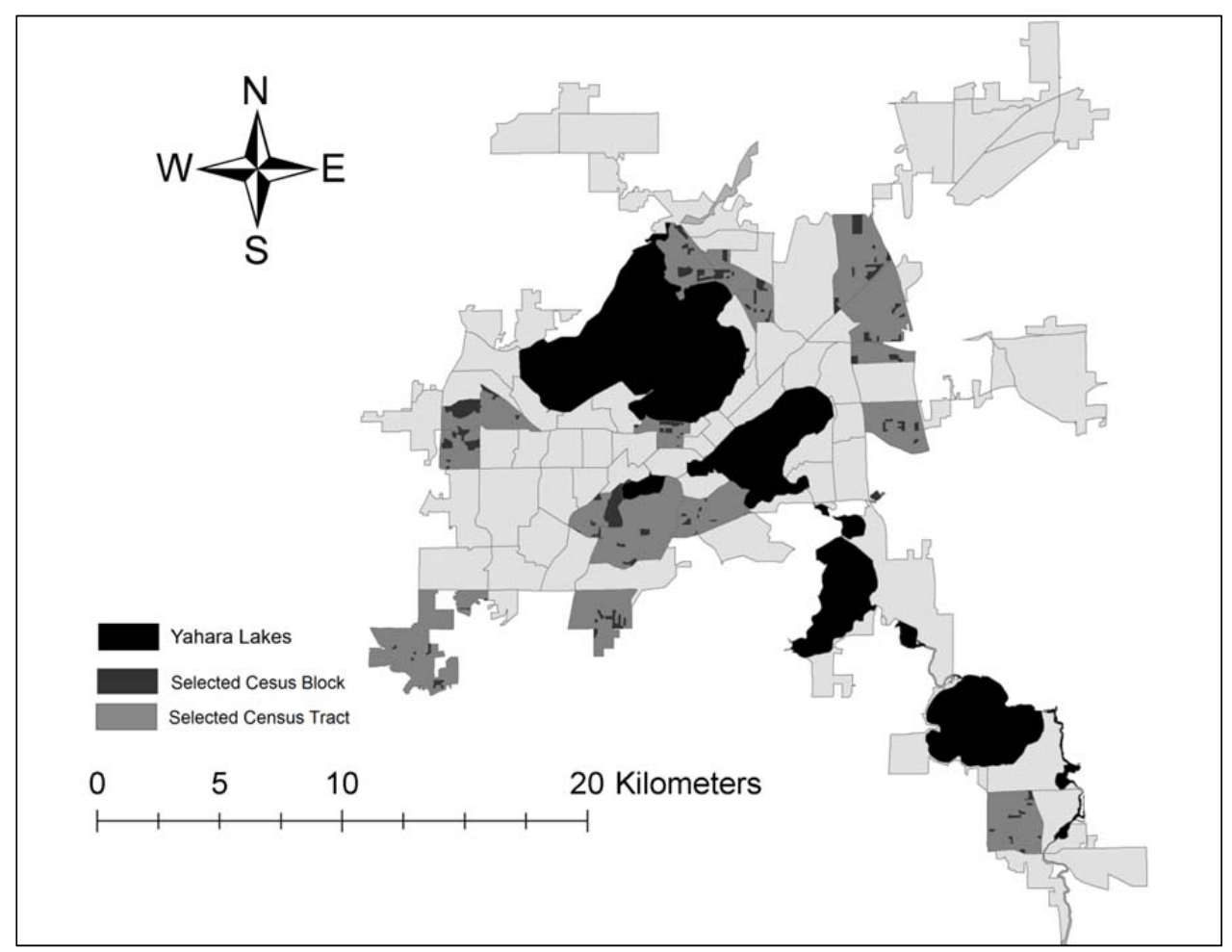


assigning each the estimated area of the tree crown.

Upon survey completion, we entered all data into a spreadsheet and joined it to a parcel shape file layer for analysis in ArcGIS, a geospatial analysis software program. We geocoded garden presence and garden size data by parcel and then aggregated each parcel by census block and census tract. We calculated garden presence in tract aggregates as a raw total number of gardens, and as a portion of gardens per population, per household, and per address identified in the survey process. Population and household estimates were drawn from the 2009 American Community Survey fiveyear estimate.

We then used the data compiled and explored in the sample to develop an estimate of garden presence in unsampled tracts throughout the study area. We used median household income, household type (single versus multifamily residences), and whether homes were owned or rented, as independent variables in single- and multivariable regression analyses. We explored all single-variable regressions as well as multivariate regressions. We used the best fit model to estimate garden presence in each of the 71 census tracts not sampled within the study.

We identified the presence of community and school gardens with the assistance of the local nonprofit organization Community Action Coalition of Southwest Wisconsin (CAC). The CAC maintains a list of all known community and school gardens along with contact information, garden location, and garden size (including number of plots, number of families served, and total area). Garden addresses were used to geocode a point layer of all gardens identified by the CAC located in the MUA.

The presence and size of home and community gardens were then analyzed against median household income as reported in the 2000 U.S. Census to explore possible patterns in gardening as a product of income. Initially gardening versus median household income was visually inspected using ArcMap. Simple linear regression models of garden presence against median household income, percent of homes owned versus rented, and percent of single-family residences, along with an analysis of variance of garden presence by income category, were used to measure the relationship between garden presence and selected variables.

\section{Community Food Production V alue}

The quality and quantity of food produced by CFP are part of its many potential values (Butterfield, 2009). While agricultural production estimates exist for large field crops, no such estimates exist for small-scale agriculture or for mixed crop systems. Furthermore, actual production in CFP depends on a number of factors not typical of market agriculture, including the intent or objective of the grower.

While traditional "researcher-tended" test plots are useful in simulating production "potential," as a measure of actual CFP production levels these plots fail in that CFP production may be influenced by unobservable factors such as level of care or satisfaction, which are unknown. The lack of data on growing practices suggests the need to observe production from gardens tended and controlled by the gardeners themselves.

In the fall of 2009 we recruited a conveniencebased stratified sample of gardeners. We identified 48 growers representing home gardens, community gardens, and school-educational gardens willing to participate in a year-long study of garden productivity. We asked all growers to join a "Madison Area Urban Agricultural Citizen Research Network" to assist in data collection. Such citizen research networks have been widely used in ecological research and have been shown to produce valid and reliable results (Cooper, Dickinson, Phillips, \& Bonney, 2007). We then trained growers over the course of three months to record time spent gardening, garden-related expenses, harvest weights, dates of harvest, and items harvested. We also provided the growers with digital scales purchased through a graduate research fellowship from Annies Inc., spreadsheet templates, and a garden journal. The spreadsheet templates and garden journal were sent both electronically and in hard copy. The spreadsheet contained a column for each day of the growing season and rows for time spent, dollars spent, harvest weight of all likely food products, and empty rows for food products not identified. The garden journal was a simple Microsoft Word document template that was printed and then used in the garden to track date, 
time spent, expenses, and garden tasks performed, including harvests. We asked growers to record all time and garden-related expenses beginning on January 1, 2010, through October 31, 2010. Growers recorded harvest data beginning on April 1, 2010. The assigned dates coincide with the growing season of the MUA.

We visited participating gardens periodically throughout the 2010 growing season both to record conditions generally and to record any variations in recording methods. Of the 48 growers originally identified to participate in the study, 36 growers completed the study. Reasons given for self-removal from the study included lack of time, relocation, and illness.

In order to estimate the market value of garden products from the weight of garden products, market prices were identified throughout the growing season. These prices were derived from 10 market visits over the course of the growing season and across several market venues. Venues included two conventional grocers, a specialty grocer carrying a large range of organic products, a food cooperative, and a farmers' market. During each of these visits we determined prices for all fruits and vegetables being sold and grown or likely to be grown in the Madison Urban Area. In addition, we identified prices for mushrooms, eggs, and honey, as these were known to be produced by urban growers in the area. We then calculated means and standard deviations for the prices of all products. In addition, we estimated calories by weight of all food items produced using the USDA's calorie estimation worksheet (Gebhardt \& Thomas, 2002).

On October 31, we collected records from all participating growers. We entered data into a spreadsheet format from hand-written garden logs for those who chose not to use a computer for record-keeping. Total number of hours spent gardening, total expenses, and total garden area were recorded for each participating gardener. In addition, we determined the weight of each item harvested over the course of the season. From the above records, we calculated the gross value of food produced (raw and per square meter of garden), net value of food produced (raw and per square meter of garden), gross value of food per hour worked, and calories of food produced (raw and per square meter of garden).

We explored the possibility that garden type (home garden, community garden, or educational garden) influences garden productivity using the nonparametric Kruskal-Wallis test of difference. We also explored whether garden size has an effect on garden productivity by area. We used gross value of food produced per square meter and net value of food produced per square meter against garden size in a single variable regression to explore impact of garden size.

Though very few studies have explored smallscale production, Blair and colleagues' 1991 study of Philadelphia community gardens did quantify production. Their estimation of yield was based on expected yield per plant from data collected by Rodale Institute researchers, and then weighted by a potential yield estimate. This potential yield estimate was, in essence, a guess at how productive a garden appeared to be based on observations by horticultural experts (Blair, et al., 1991). The methods employed here are more labor-intensive and rely heavily on the assistance of citizen researchers, but assess actual yield rather than an estimated yield. Cleveland, Orum, and Ferguson (1985) estimated home garden productivity using observed harvest data but reported on only two home garden plots.

Our decision to utilize citizen researchers was based on the need to access private lands, the need for daily recording of personal data, and a desire to engage the community in research designed to impact that community. The increasingly humandominated landscape demands approaches to ecological research that include the impact of private property. Citizen science is a clear way of including private landowners in research, thereby expanding research to include lands that might otherwise be inaccessible, or in this case, an entire land use (home gardening) that would be otherwise inaccessible (Cooper et al., 2007). Furthermore, citizen scientists also tend to lend legitimacy to scientific research for the general public and make that science accessible through their own story and information sharing (Couvet, Jiguet, Julliard, Levrel, \& Teyssedre, 2008). 


\section{Estimating Community Food Production Resources}

We used the relationship established in our regression analysis between garden presence and homeownership as well as average garden size to estimate the total area under production within our study area. We then estimated the agricultural productivity of the study area based on the production means from the citizen-science test plots. The result is an estimate of the total gross value, net value, and calories produced through CFP within the MUA.

The absolute contribution of CFP in terms of gross market value, net market value, and calories is of significant importance in understanding overall value. However, it is the relative contribution of CFP in comparison to total food needs that is most relevant to its role as a form of community

Table 1. Home Garden Frequency and Mean Garden Size of Census Tracts by Ascending 1999 Median Household Income as Reported in the U.S. Census

Means are identified in bold for all census tracts sampled. Likelihood of participation in home gardening appears to decrease as median household income decreases.

\begin{tabular}{cccccc}
\hline $\begin{array}{c}\text { Tract Median } \\
\text { Household } \\
\text { Income (US } \$ \text { ) }\end{array}$ & $\begin{array}{c}\text { Observed } \\
\text { Gardens }\end{array}$ & $\begin{array}{c}\text { Percent of } \\
\text { Population } \\
\text { Practicing }\end{array}$ & $\begin{array}{c}\text { Percent of } \\
\text { Households } \\
\text { Practicing }\end{array}$ & $\begin{array}{c}\text { Percent of } \\
\text { Addresses } \\
\text { Practicing }\end{array}$ & $\begin{array}{c}\text { Mean Garden } \\
\text { Area }\left(\mathbf{m}^{2}\right)^{\text {a }}\end{array}$ \\
\hline$\$ 15,369$ & 4 & N/A & 11 & 25 & $41^{*}$ \\
\hline$\$ 26,173$ & 7 & 3 & 12 & 10 & 10 \\
\hline$\$ 34,210$ & 32 & 14 & 30 & 31 & 8 \\
\hline$\$ 36,913$ & 19 & 12 & 29 & 21 & 12 \\
\hline$\$ 40,104$ & 52 & 13 & 30 & 25 & 8 \\
\hline$\$ 42,473$ & 39 & 14 & 35 & 34 & 9 \\
\hline$\$ 44,896$ & 27 & 6 & 14 & 17 & 10 \\
\hline$\$ 50,310$ & 99 & 9 & 20 & 26 & 10 \\
\hline$\$ 52,500$ & 23 & 2 & 45 & 47 & 7 \\
\hline$\$ 53,442$ & 42 & 13 & 41 & 30 & 10 \\
\hline$\$ 56,026$ & 30 & 14 & 35 & 30 & 14 \\
\hline$\$ 60,552$ & 37 & 12 & 36 & 36 & 5 \\
\hline$\$ 66,810$ & 46 & 14 & 38 & 26 & 11 \\
\hline$\$ 71,341$ & 31 & 12 & 34 & 32 & 6 \\
\hline$\$ 79,035$ & 60 & 10 & 31 & 28 & 15 \\
\hline$\$ 83,112$ & 108 & 9 & 27 & 26 & 15 \\
\hline$\$ 50,829$ & 41 & 10 & 29 & 28 & 12 \\
\hline$\$ 50$ & & & & &
\end{tabular}

* Based on four unusually large public gardens on or near a college campus

a $1 \mathrm{~m}^{2}=10.8$ feet $^{2}$ food security. We calculated both the estimated total caloric needs of the study area and the estimated expenses on groceries to determine how the contribution from CFP compared to total need. Estimates of total caloric need were derived from the USDA's Food Intake Calorie Levels table (USDA, Center for Nutrition Policy and Promotion, 2005). The population in each age category within the MUA was taken from the U.S. Census Bureau's Community Survey (U.S. Census Bureau, 2009). We used these two data sets together to estimate the total caloric need of the MUA, accounting for age and gender. A similar analysis was conducted for food expenses using the USDA's Meal Plan Expenses estimation (Center for Nutrition Policy and Promotion, n.d.). The average monthly meal plan costs are given within the USDA's Meal Plan table for four different "meal plans." Estimated expenses were calculated based on the "moderate" meal plan. Estimates were again combined with census data describing MUA's population age and gender. The resulting data provide an estimate of the total expenses on groceries within the study area, accounting for age and gender. A comparison of the estimated total caloric need and grocery expenditures for the study area makes it possible to estimate the relative contribution of CFP in terms of market value and caloric value.

The methods we used here to calculate relative contribution to community food security are based on total food costs and total caloric need as a baseline. It may also be useful to calculate the relative contribution against a list of likely agricultural products, such as against the total cost of fruits and vegetables, as 
has been calculated in a past study (MacRae et al., 2012). We chose not to calculate relative contribution in this way due to the difficulty of determining the "appropriate" market value and caloric contribution of fruits and vegetables relative to total dietary needs.

\section{Results}

\section{Garden Presence}

The raw number of gardens found within each tract, the average size of gardens, and the ratio of gardens to population, households, and addresses are outlined in table 1 and described visually in figures 4 and 5 . The raw number of gardens identified was far greater than originally anticipated but consistent with national estimates of home food production estimated by the National Gardening Association (Butterfield, 2009).

Census blocks are based on neither population nor area. Thus the raw number of home gardens identified does not adequately characterize the propensity for gardening in a block due to variation in block area, population, and number of households in each block. Therefore, we used "gardens per household" to communicate the degree to which CFP
Figure 4. Sampled Home Garden Presence

Total number of sampled home gardens tends to increase with distance from urban center.

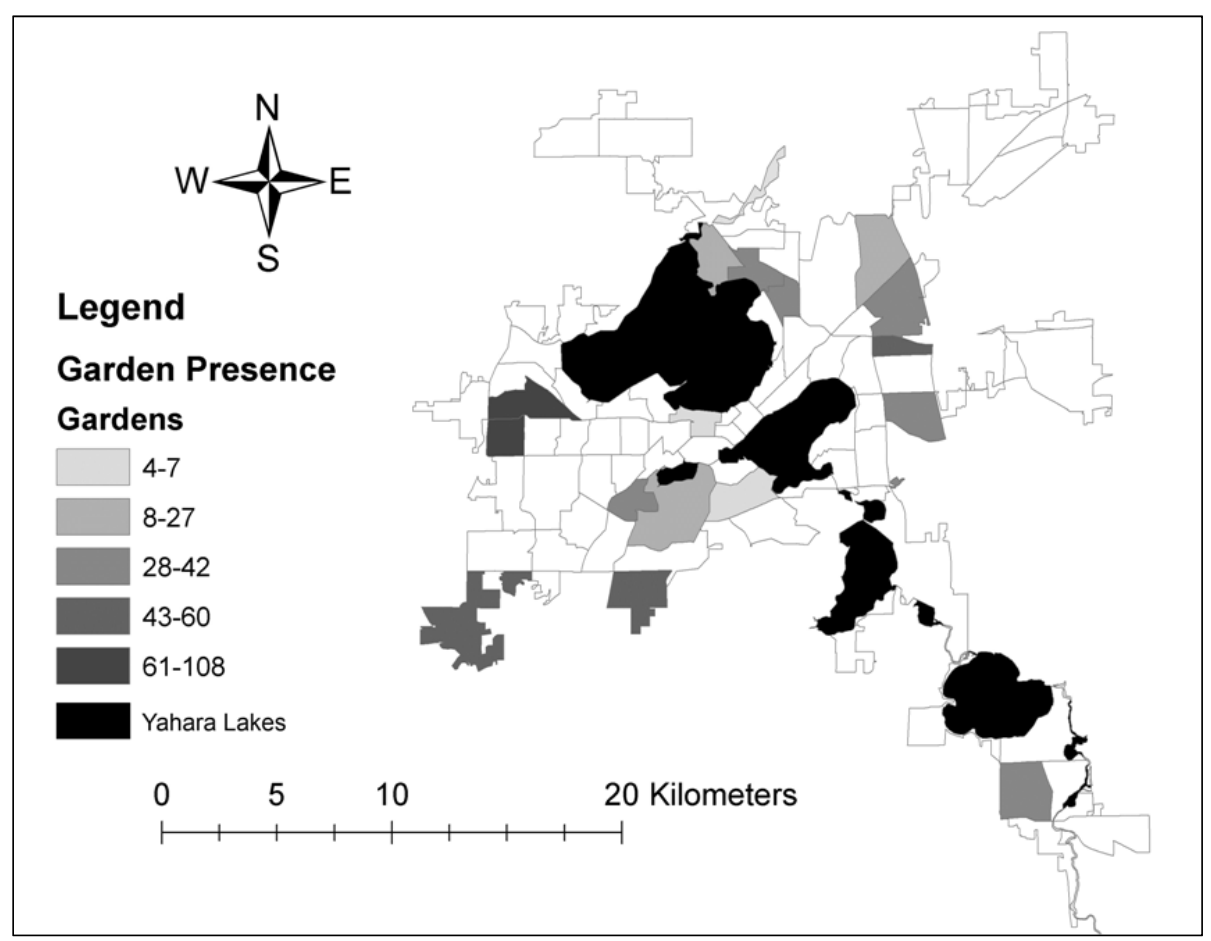

Figure 5. Percent of Households Participating in Home Gardening Sampled percent of households participating in home gardening tends to increase with distance from urban center.

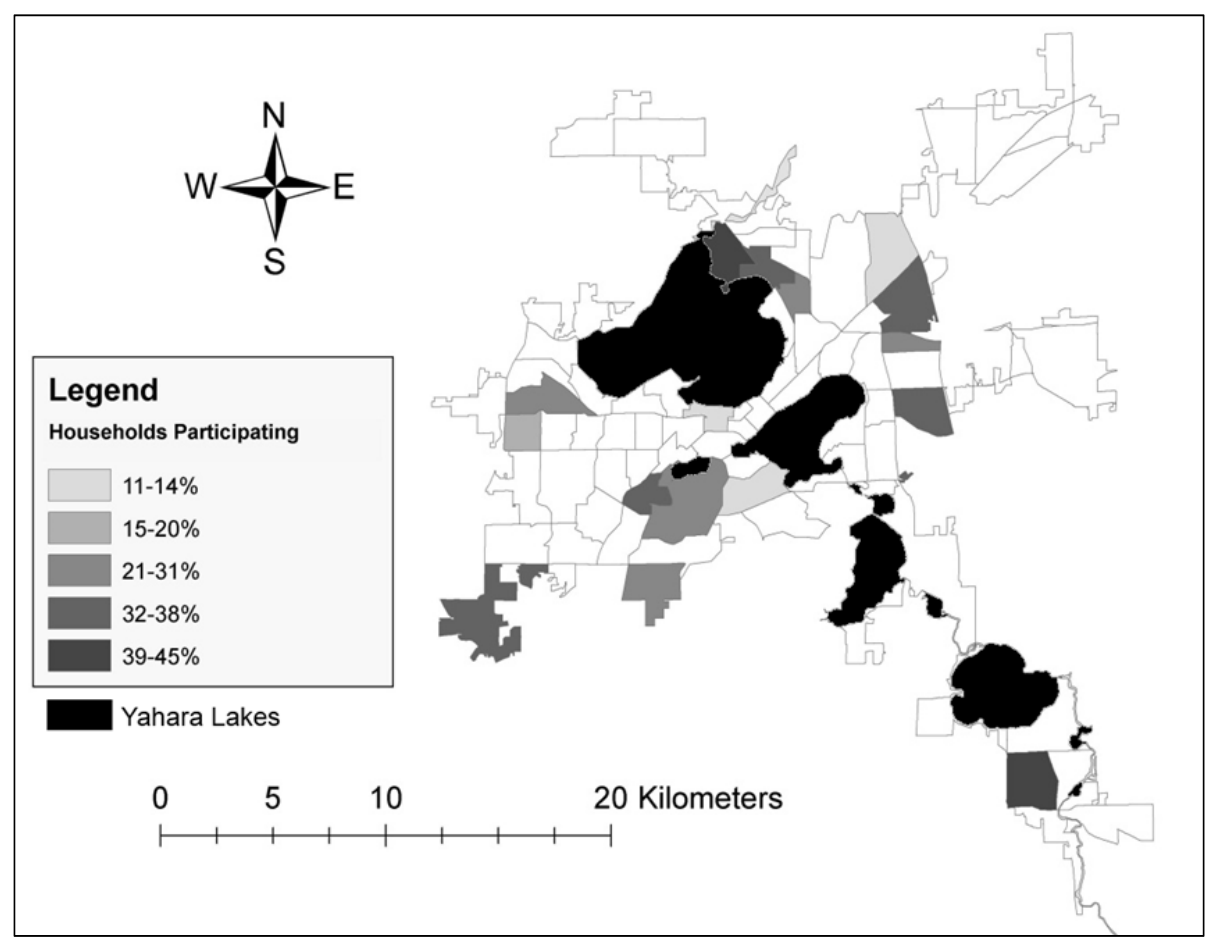


Table 2. Results of Linear Regression Models of Garden Frequency Versus Tract Characteristics

The resulting fit of the model vs. observed data in sampled tracts is additionally shown. All variables have a positive linear relationship with home garden participation.

\begin{tabular}{lccc}
\hline Model & R squared & F statistic & P value \\
\hline Income & 0.219 & 5.211 & $.039 *$ \\
\hline Ratio Single-Family Unattached & 0.291 & 7.147 & $.018^{*}$ \\
\hline Ratio Homeownership & 0.358 & 9.354 & $.009 *$ \\
\hline
\end{tabular}

* Statistically significant

Figure 6. Scatter Plot and Fitted Line of Garden Presence as a Product of Tract-Level Median Household Income Home garden presence increases as household median income of census tract increases.

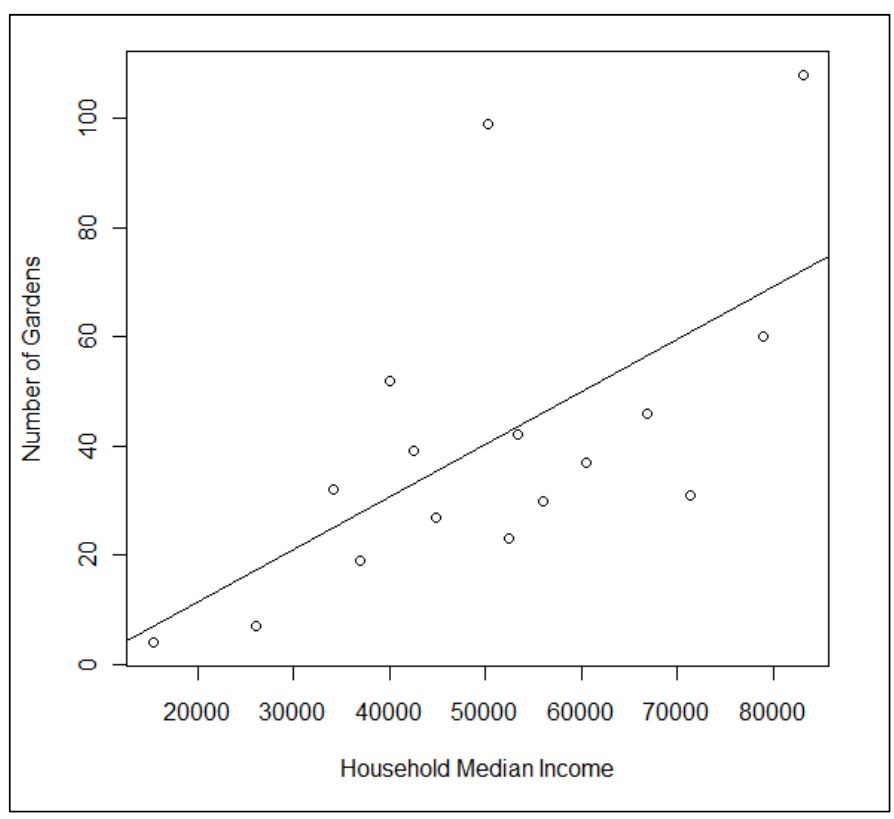

was practiced in a block. The number of households participating in gardening was used as a realistic quantifiable estimate of the degree to which gardening is utilized within a community. Gardens per population followed a nearly identical trend, but less clearly illustrate the likelihood of a household unit to garden, as household size varies across the landscape. Gardens per address sampled appeared almost identical to gardens per household but additionally captures land use types on which gardens were unlikely to be found.

The degree to which gardens occur on commercial or industrial land was difficult to determine due to a lack of commercial or industrial land uses within the sample set and very low garden observations on these land use types. "Gardens per household," therefore, was deemed the best indicator of the likelihood of a community to garden. The ratio of "gardens per household" was translated into percent of households participating for

ease in reporting.

\section{Estimating Home Garden Frequency}

We used sampled data to estimate the number of home food gardens across the study area. Based on observation during the surveying procedure, gardens appeared more frequently as income increased. The regression analysis shows home garden presence to be correlated with median household income, ratio of single-family unattached homes, and ratio of homeownership over rental, as shown in table 2. These three highly correlated demographic variables all have statistically significant linear relationships with the presence of home gardens per household.

Although we explored single-variable regressions as well as all combinations of multivariate regressions, a simple singlevariable model using homeownership best estimates gardens per household. A similar study in 1983 also noted that community characteristics, including income and whether the home was rented or owned, best predicted the decision to grow food at home (Blaylock \& Gallo, 1983). Though homeownership best estimates gardens per household, median household income as a correlate of homeownership is often useful to understand garden presence and is shown in figure 6 .

The resulting model of gardens per household indicates that the number of gardens per tract range from 162 to 1,196, and the percent of households participating in home gardens ranges from 15 percent to 41 percent across the study area, as shown in figures 7 and 8. 
The positive correlation between home garden presence and median household income is visually depicted in figure 9. This configuration is opposed, in many ways, to the present configuration of community gardens as shown in figure 10, which historically have been located in census tracts with low median household incomes. The presence of community gardens in lower-income census tracts, however, is not specifically an indicator of gardener income as it is unclear where gardeners in these community gardens live. Nevertheless, the results of self-reported questionnaires (Smith, 2011) suggest that community gardens serve a lower-income population than do home gardens.

\section{Harvest Data}

The 36 citizen scientist gardeners completing the study recorded daily harvest data, expense data, and time data under researcher direction. Seasonal results are reported in table 3.

A Kruskal-Wallis nonparametric analysis of variance showed no significant differences in production between garden types. All garden types (home, community, educational) had similar production levels per area. The produce weight per square meter reported was based on the weight of washed and trimmed product. In most cases, this referred to fresh fruits or vegetables,
Figure 7. Estimated Number of Home Gardens by Census Tract Garden presence increases as distance from urban center and median household income increase.

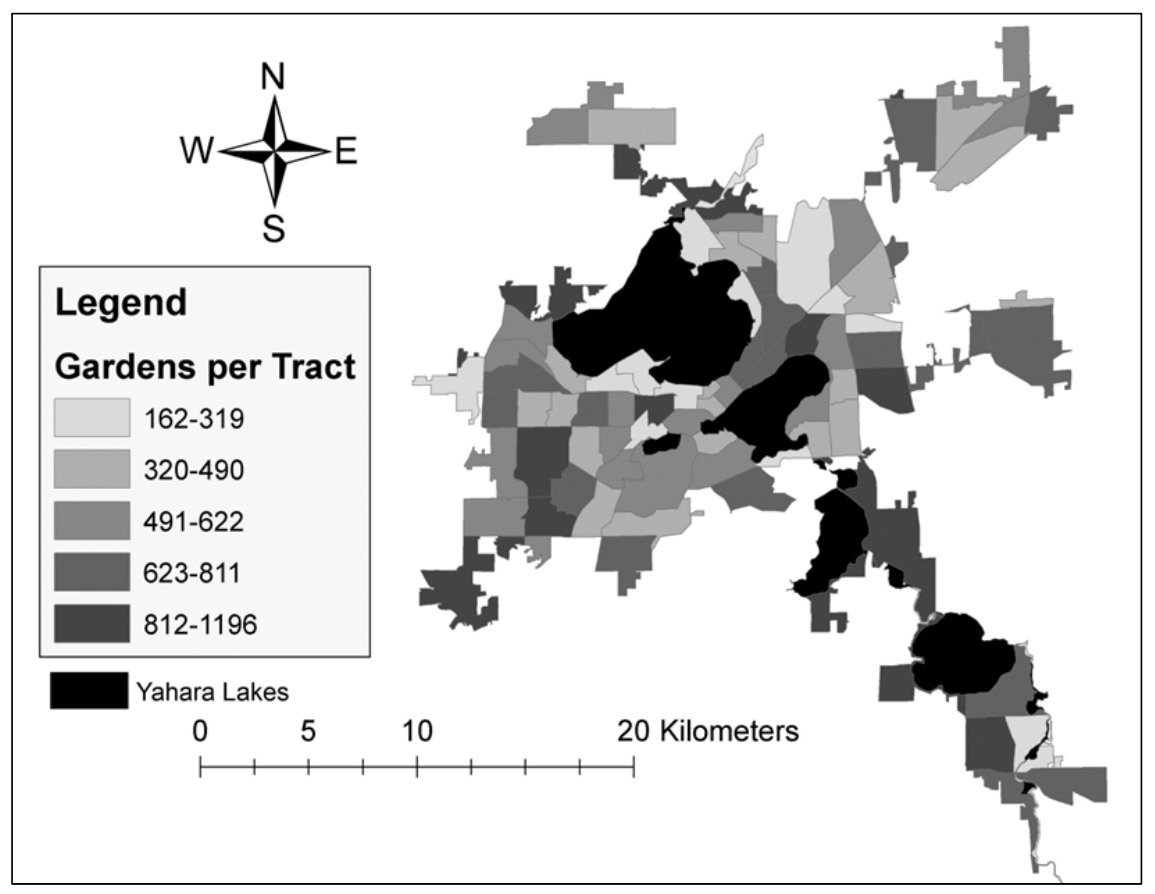

Figure 8. Percent of Homes Participating in Home Gardening by Census Tract

Percent of households participating increases as distance from urban center and median household income increase.

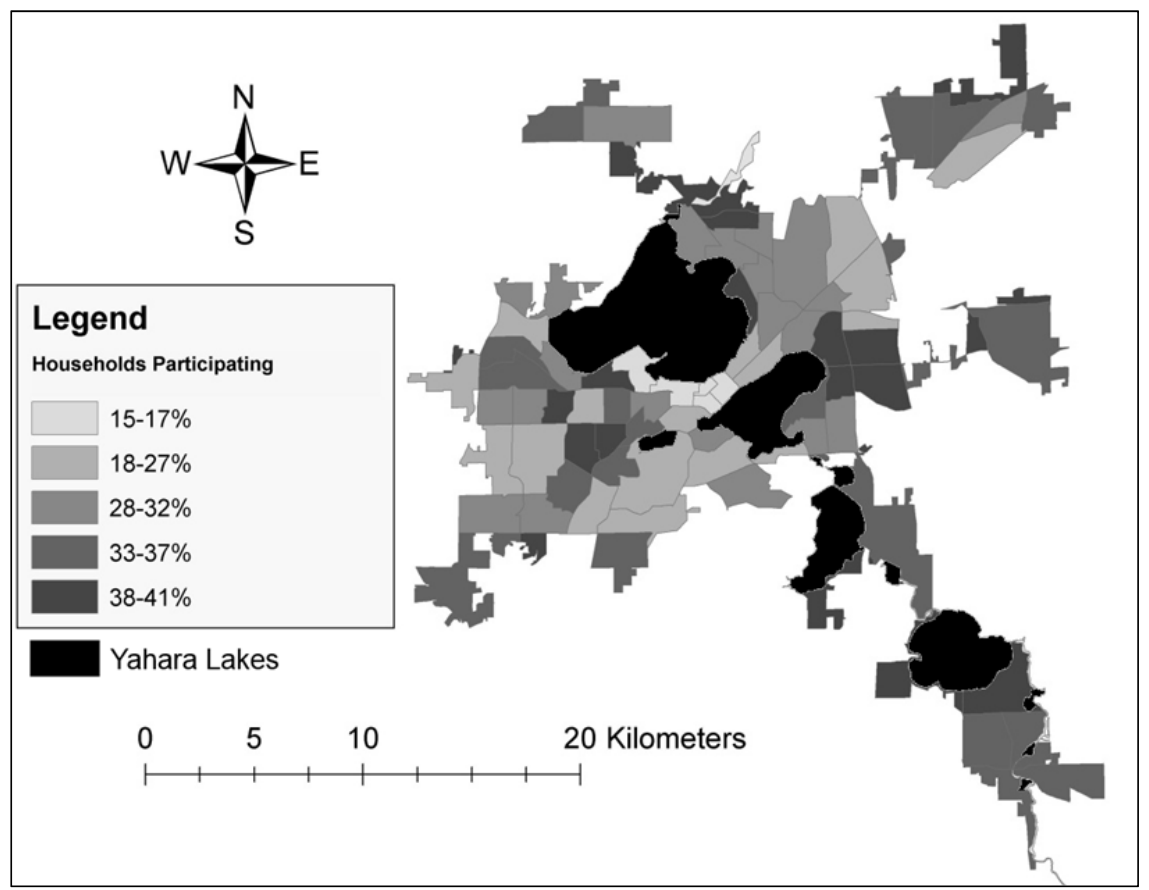


Figure 9. Home Garden Participation with Median Household Income by Census Tract

Likelihood of participation increases as median household income increases.

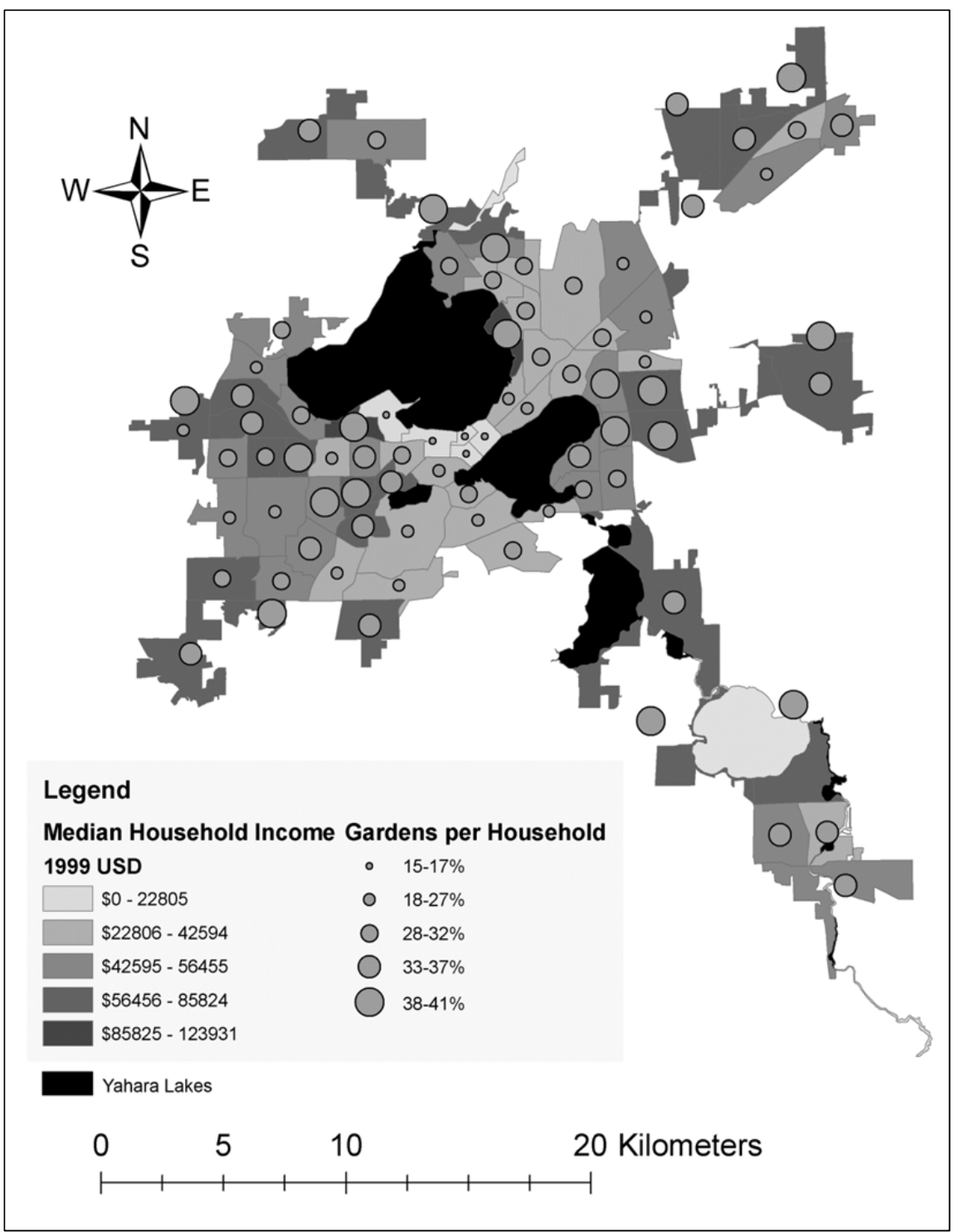

Extrapolating Harvest Data

By extrapolating the production data of the 36 test plots to the CFP resources identified through surveying, we were able to estimate all CFP production resources in the MUA. This estimate is based on the total actual number of known community and school gardens and their known sizes. In addition, it is based on the sample estimate number of home gardens and mean sample size. The mean production value for each of these production types is then drawn from the test plot samples and applied to the area as a whole in table 4

Though the absolute number of CFP resources and their resulting caloric and dollar values are high, the relative contribution of these resources in terms of total food expenses or caloric need is quite low. Based on an estimate of food expenses drawn from the USDA meal plan expense chart (USDA, Center for Nutrition Policy and Promotion, n.d.), the total estimated annual cost of food purchases for the MUA totals although some gardeners additionally reported production of mushrooms, eggs, and honey. Calorie values were derived from the calories per gram weights recorded in the USDA's caloric estimation for use in food labeling (USDA, Agricultural Research Service, n.d.) and then converted to calories per kilogram. Though these estimates are known to vary with growing conditions, soil, and variety, they represent the best estimate of caloric output of these gardens.
US $\$ 11,903,176,861$. Therefore all CFP resources combined contribute .08 percent of the area's annual food expenditures. As an estimate of total caloric need for the MUA $(272,627,175,174$ calories) (Center for Nutrition Policy and Promotion, 2005), that number increases to .14 percent. As noted above, these estimates were determined by calculating both caloric need and estimated expenses by both age and gender for the study area as a whole. Population structure was calculated based on the 2009 Community Survey five-year estimate. 
Figure 10. Community Gardens with Median Household Income by Census Tract

Community garden presence appears distributed across median household income; however, many appear in areas of low median household income.

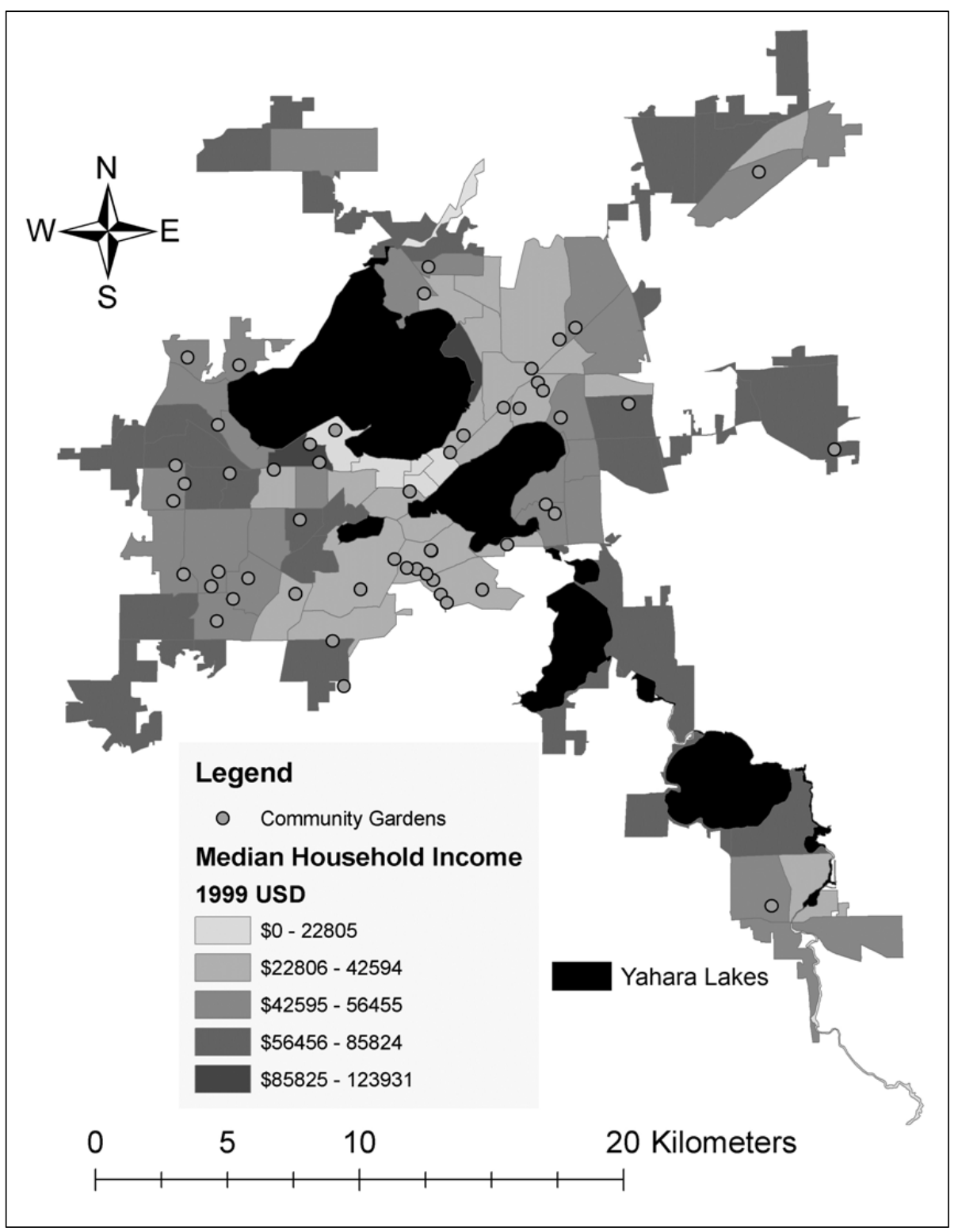

that the frequency of this practice is related to demographic and household variables, such as median household income, as has been found in similar studies (Meenar \& Hoover, 2012; Mirsch \& Dimitri, 2012). For some Madison neighborhoods, the proportion of households gardening is as high as 41 percent. In other areas, however, that proportion is much lower (15 percent of households). Household income, whether a home is a single-family unattached house, and whether the home is owned or rented all inform whether a home garden will be present. CFP increases with household median income, homeownership, and unattached homes as shown in table 2 and figure 6 . We limited our use of regression analysis in this study to provide a simple estimate of how CFP impacts community food security. More robust regression models could be developed using demographic variables to better predict likelihood

\section{Discussion}

Thirty-three percent of households in the Madison Urban Area participate in CFP in some way. This is consistent with data collected by the National Gardening Association, which estimates that 31 percent of all U.S. households, or an estimated 36 million households, participate in CFP each year; this number continues to climb each year (Butterfield, 2009). However, this research suggests of garden presence in a specific area. Our findings here are meant to help generally quantify CFP contribution.

In total, there are an estimated 45,193 home food-producing gardens in the Madison area totaling 491,219 square meters $(5,287,437$ square feet). The average home garden size was 12 square meters (129 square feet), suggesting that for many, especially for apartment dwellers, these gardens are 
Table 3. Productivity of CFP Resources Aggregated by Resource Type Shown with Kruskal-Wallis p-Values of Variance Between Aggregation Types

\begin{tabular}{|c|c|c|c|c|c|c|}
\hline & $\begin{array}{l}\mathrm{Kg} / \\
\mathrm{m}^{2}\end{array}$ & $\begin{array}{c}\text { Dollars/ } \\
\mathrm{m}^{2}\end{array}$ & $\begin{array}{c}\text { Dollars/ } \\
\text { Hour }\end{array}$ & $\begin{array}{c}\text { Net Dollars/ } \\
\mathrm{m}^{2}\end{array}$ & $\begin{array}{c}\text { Hours/ } \\
\mathrm{m}^{2}\end{array}$ & $\begin{array}{c}\text { Calories/ } \\
\mathrm{m}^{2}\end{array}$ \\
\hline \multicolumn{7}{|l|}{ Home Gardens $(n=13)$} \\
\hline Mean & 2.13 & 15.79 & 17.01 & 11.65 & 1.06 & 627.99 \\
\hline$\overline{\mathrm{SE}}$ & 0.51 & 3.71 & 3.13 & 3.15 & 0.34 & 112.82 \\
\hline $95 \mathrm{Cl}$ & $1.12-3.12$ & $8.51-23.03$ & $10.86-23.15$ & $5.49-17.86$ & $.43-1.72$ & $406.84-849.07$ \\
\hline \multicolumn{7}{|l|}{ Community Gardens ( $n=14)$} \\
\hline Mean & 2.06 & 15.19 & 13.58 & 13.05 & 1.43 & 742.30 \\
\hline SE & 0.34 & 2.11 & 2.36 & 2.10 & 0.14 & 144.82 \\
\hline $95 \mathrm{Cl}$ & $1.42-2.73$ & $11.08-19.36$ & $8.96-18.21$ & $8.93-17.22$ & $1.18-1.72$ & $458.27-1026.29$ \\
\hline \multicolumn{7}{|l|}{ Educational Gardens $(n=5)$} \\
\hline Mean & 1.40 & 8.13 & 11.57 & 5.27 & 1.06 & 457.29 \\
\hline$\overline{S E}$ & 0.22 & 3.95 & 1.84 & 4.37 & 0.29 & 233.56 \\
\hline $95 \mathrm{Cl}$ & $.98-1.85$ & $.44-15.81$ & $7.97-15.18$ & $-3.34-13.88$ & $.54-1.61$ & $0-915.03$ \\
\hline \multicolumn{7}{|l|}{ All Gardens $(n=36 *)$} \\
\hline Mean & 1.91 & 13.79 & 14.31 & 10.68 & 1.26 & 619.79 \\
\hline$\overline{\mathrm{SE}}$ & 0.05 & 1.82 & 1.59 & 1.60 & 0.15 & 75.91 \\
\hline $95 \mathrm{Cl}$ & $1.45-2.39$ & $10.22-17.32$ & $11.20-17.43$ & $7.53-13.77$ & $.97-1.61$ & $471.07-768.59$ \\
\hline Kruskal-Wallis p-value** & 0.35 & 0.27 & 0.37 & 0.32 & 0.21 & 0.45 \\
\hline
\end{tabular}

* Total includes 4 plots reporting on both home and community gardens

** No significant differences were detected between garden types

nothing more than a few potted plants or a row of beans running along a fence. For others, however, the gardens are much larger — as large as 400 square meters (4,306 square feet).

Community gardens and school gardens are also found throughout the area, and their placement is also related to median household income, although in this case they are found more frequently in areas with lower median household incomes (see figure 10). Community gardens, particularly older ones, tend to exist in precisely the opposite locations as home gardens. However, unlike home gardens that are tended by on-site residents, it is unclear whether members of a community garden live in the community in which that garden is located. Several community garden registrars report residents traveling from outside the neighborhood to garden. Several community gardeners interviewed in this study lived 30 minutes or more by car from the community garden (Smith, 2011). They chose the community garden based on proximity to a major road used in their daily commute to and from work.

There are 52 known community gardens and school gardens in the area, totaling 2,991 total plots or 110,551 square meters $(1,189,961$ square feet). Community gardens and school gardens represent only 6.2 percent of the total number of gardens, but they represent 18.4 percent of the total land area of CFP. The mean size of a community garden plot tends to be much larger than a home garden. This is due to the fact that home gardens in this study were defined as any food production at the home regardless of size. Many of these gardens were only a few potted plants on a balcony.

There are a total of 48,184 CFP resources (gardens) in the Madison area covering 601,770 square meters $(6,477,398$ square feet). As a whole, CFP resources in the area gross US $\$ 13.79$ per square meter, net $\$ 10.68$ per square meter, and produce $1.91 \mathrm{~kg}$ per square meter. This appears to be consistent with what other researchers have 
found. For instance, Doiron (2009) found that a home garden could produce US $\$ 1.50$ per square foot (US\$16.15 per square meter). In the arid U.S. Southwest, home gardens were found to net between US\$109 and US $\$ 123$ per year, or to produce between 1.24 and $2.31 \mathrm{~kg} /$ square meter $(0.25$ and 0.47 $\mathrm{lb} /$ square foot) (Cleveland et al., 1985). Finally, the National Gardening Association's 2009 national report estimated CFP to produce 0.5 pounds per square foot ( 2.42 kilograms per square meter) at an estimated US $\$ 2.00$ per pound (US $\$ 4.41$ per kilogram) or US $\$ 1.00$ per square foot (US $\$ 10.60$ per square meter)

(Butterfield, 2009).

The latitude of Madison, Wisconsin, is 43 degrees North. According to the Wisconsin State Climatology Office, the median length of the growing season between 1971 and 2000 was 147 days, which is lower than for much of the United States. Though the length of the growing season alone is not an accurate measurement of agricultural productivity potential, it is important to recognize that the location of our study area plays an important role in interpreting our results.

In all but two cases in this study, the CFP practitioners experienced positive net returns on their investments. In most cases the return on investment was relatively high. In terms of net market value of food produced per hour spent on CFP, the mean dollar per hour return was US $\$ 14.31$. Table 3 breaks down the productivity of CFP by home gardens, community gardens, and school gardens by way of illustration. However, the differences in production between these garden types are quite small and not statistically significant.

\section{Conclusions}

The 48,184 gardens in the Madison Urban Area contributed a gross agricultural product of US $\$ 9.4$ million in 2010. In terms of net production, that is US\$7.1 million. The absolute contribution of these gardens, however, whether measured in pounds, dollars, or calories, is not enough evidence alone that CFP is playing an important role in food security. Organizations have a tendency to publish this kind of data with bountiful pride and argue that they have solved food insecurity. With over 300,000 people in the Madison Urban Area, the substantial absolute contribution of food through CFP amounts to .08 percent of the total food needs in terms of dollars or .14 percent of total caloric need.

The percentages of total caloric need and food expenses listed here are for the Madison Urban Area as a whole. However, it is additionally helpful to understand how much of a CFP practitioner's average food expenses or caloric need are met through his or her participation in CFP. In this case, the estimated percent of food expenses provided by CFP for practitioners is 2.4 percent. The actual present contribution and the contribution potential, however, are quite different due to substantial variation in garden size. The largest home gardens in this study, for example, were 
actually producing more in terms of both dollars and calories than the household would have needed. Though these households were still purchasing some food items, in terms of dollars and calories they were self-sufficient from their backyard garden alone. Most individual households do not have the yard space or time to produce at this level, but the potential for CFP as a meaningful contributor to the total food supply does exist.

The relative versus absolute contribution of CFP is important in assessing the role of CFP as a component of community food insecurity. From the community or regional perspective, the current contribution of CFP is relatively small. However, from the perspective of the individual or household participating in CFP, market value and/or caloric contribution can be a substantial component of food security. For example, even a garden as small as the average 12.5 square meters or 135 square feet (the mean for all garden types) returns over US $\$ 100$ in food per year. Some may find this value meaningful, but others may not find that US $\$ 100$ is worth the time or initial investment.

This discovery, that the contribution of the food itself is quite small, is not entirely novel. Others have found the same, including community food security advocate Mark Winne, who argued,

A little patch of green sprouting in an otherwise unforgiving urban landscape is desirable for many reasons, not the least of which is the relief it gives the eye. But... Hartford's community gardens have made only a marginal contribution to the city's food security, with the exception of a relatively small number of ardent gardeners who have significantly augmented their food supplies. (Winne, 2008, p. 57)

The case of Madison seems to be similar to Hartford; the food itself is making only a small contribution in terms of the community's overall food security. However, the market value and caloric contribution of CFP per unit area suggests that the potential for CFP to contribute meaningfully to community and household food security is substantial. Findings here are consistent with similar research in Toronto that has suggested the need for scaling up production to meet food insecurity demands (Patel \& MacRae, 2012).

Further research is likely necessary to quantify the current market value of CFP in other municipalities or regions as well as the potential role of $\mathrm{CFP}$ in the future. Employing the methods described here on a regular basis would be both time-consuming and costly. However, as CFP expands it will be necessary for regional food system planners to consider the rigorous methods employed here on a periodic basis to better understand the overall growth of CFP and its spatial distribution.

Our attempts to simplify identification of CFP through the use of aerial photography proved unsuccessful due to the current resolution of imagery. Any future attempts to utilize aerial or satellite-based imagery will need to depend on image resolution and data processing power beyond that which is currently regularly available. Furthermore, our research suggested that even well networked community leaders and neighbors were unable to identify where food production was taking place within a neighborhood with which they were highly familiar. This again suggests the need to resist attempts to simplify data collection procedures by relying on key informants if reliable food production data is needed.

The limited extent to which CFP is currently contributing to municipal and/or regional food demands is unlikely to warrant the level of research investment employed here throughout urban areas broadly. However, if program-level or site-specific data is needed, use of the methods employed here may be highly beneficial. Better understanding the current contribution of individual community gardens, urban farms, and even backyard gardens will be necessary to model the future potential of CFP to contribute to food security; this potential was demonstrated here by virtue of the high productivity of specific CFP resources.

The limited contribution of CFP at the municipal and/or regional level relative to its potential as a source of food security suggests the need for further research to explore the current barriers to participation. This same recommendation was additionally reported in research in 
Toronto (MacRae et al., 2012). Better understanding the social, political, and environmental factors limiting production and expansion of CFP will be necessary to plan for or develop future resources. In addition, a continued focus on social and geographic distribution of resources will be necessary to measure the extent to which expanded resources meet the needs of intended audiences.

Our research lends clarity to the ongoing debate about whether urban production may serve as a form of community food security by quantifying the relative and absolute contribution within one region. Further quantitative research will be needed to extend the results of our research nationally or internationally.

\section{References}

Bellows, A. C., Brown, K., \& Smit, J. (2003). Health benefits of urban agriculture. Community Food Security Coalition. Retrieved from http://www.foodsecurity.org/UAHealthArticle.pdf

Blaylock, J. R., \& Gallo, A. E. (1983). Modeling the decision to produce vegetables at home. American Journal of Agricultural Economics, 65(4), 722-729. http://dx.doi.org/10.2307/1240460

Blair, D., Giesecke, C. C., \& Sherman, S. (1991). A dietary, social, and economic evaluation of the Philadelphia Urban Gardening Project. Journal of Nutrition Education, 23(4), 161-167. http://dx.doi.org/10.1016/S0022-3182(12)81191-5

Brown, K. H., Bailkey, M., Meares-Cohen, A., Nasr, J., Smit, J., \& Buchanan, T. (2002). Urban agriculture and community food security in the United States: Farming from the city center to the urban fringe. Venice, California: Urban Agriculture Committee of the Community Food Security Coalition. Retrieved from http://afsic.nal.usda.gov/farms-andcommunity/urban-agriculture

Bruinsma, W., \& Hertog, W. (2003). Annotated bibliography on urban agriculture. Leusden, The Netherlands: ETC Urban Agriculture Programme. Retrieved from the RUAF website: http://www.ruaf.org/sites/default/files/annotated bibliography.pdf

Butterfield, B. (2009). The impact of home and community gardening in America. South Burlington, Vermont: National Gardening Association. Retrieved from http://www.garden.org/
Cleveland, D. A., Orum, T. V., \& Ferguson, N. F. (1985). Economic value of home vegetable gardens in an urban desert environment. HortScience, 20(4), 694-696.

Cohen, B. (2002). USD A community food security assessment toolkit [ERS Report No. E-FAN-02-013]. Washington, D.C.: USDA, Economic Research Service. Retrieved from http://www.ers.usda.gov

Cooper, C. B., Dickinson, J., Phillips, T., \& Bonney, R. (2007). Citizen science as a tool for conservation in residential ecosystems. Ecology \& Society, 12(2), 11. http://www.ecologyandsociety.org/vol12/iss2/ $\underline{\operatorname{art11/}}$

Couvet, D., Jiguet, F., Julliard, R., Levrel, H., \& Teyssedre, A. (2008). Enhancing citizen contributions to biodiversity science and public policy. Interdisciplinary Science Reviews, 33(1), 95-103. http://dx.doi.org/10.1179/030801808X260031

Davis, G. C., \& You, W. (2011). Not enough money or not enough time to satisfy the Thrifty Food Plan? A cost difference approach for estimating a moneytime threshold. Food Policy, 36(2), 101-107. http://dx.doi.org/10.1016/i.foodpol.2010.09.001

Doiron, R. (2009, March 2). What's a home garden worth? [Web log post]. Retrieved from http://kgi.org/blogs/roger-doiron/home-gardenworth

Draper, C., \& Freedman, D. (2010). Review and analysis of the benefits, purposes, and motivations associated with community gardening in the United States. Journal of Community Practice, 18(4), 458-492. http://dx.doi.org/10.1080/10705422.2010.519682

Eriksen-Hamel, N., \& Danso, G. (2010). Agronomic considerations for urban agriculture in southern cities. International Journal of Agricultural Sustainability, 8(1-2), 86-93. http://dx.doi.org/10.3763/ijas.2009.0452

Food and Agriculture Organization [FAO] of the United Nations. (2010). Fighting poverty and hunger: What role for urban agriculture? (Economic and Social Perspectives Policy Brief 10). Retrieved from http://www.fao.org/economic/es-policybriefs/ briefs-detail/en/?no_cache $=1 \&$ uid $=45052$

Gautam, R., Suwal, R., \& Sthapit, B. R. (2009). Securing family nutrition through promotion of home gardens: Underutilized production systems in Nepal. Acta Horticulturae, 806(1), 99-106. http://www.actahort.org/books/806/806 10.htm 
Gebhardt, S., \& Thomas, R.G. (2002). Nutritive value of foods [Home and Garden Bulletin No. 72]. Washington, D.C.: USDA, Agricultural Research Service. Retrieved from http://www.ars.usda.gov/ Services $/$ docs.htm?docid $=6282$

Hallsworth, A., \& Wong, A. (2013). Urban gardening: a valuable activity, but.... Journal of Agriculture, Food Systems, and Community Development, 3(2), 11-14. http://dx.doi.org/10.5304/jafscd.2013.032.010

Hamm, M. W., \& Bellows, A. C. (2003). Community food security and nutrition educators. Journal of Nutrition Education and Behavior, 35(1), 37-43. http://dx.doi.org/10.1016/S1499-4046(06)60325-4

Khandaker, M. S. I. (2004). Rooftop gardening as a strategy of urban agriculture for food security: The case of Dhaka City, Bangladesh. Acta Horticulturae, 643, 241-247.

Johnson, R., Aussenberg, R. A., Cowan, T. (2013). The role of local food systems in U.S. farm policy. Washington, D.C.: Congressional Research Service. Retrieved from www.fas.org/sgp/crs/misc/R42155.pdf

Kirkpatrick, S. I., \& Tarasuk, V. (2009). Food insecurity and participation in community food programs among low-income Toronto families. Canadian Journal of Public Health, 100(2), 135-139. http://journal.cpha.ca/

Lawson, L. J. (2005). City bountiful: A century of community gardening in America. Berkeley, California: University of California Press.

MacRae, R., Nasr. J., Kuhns, J., Baker, L., Christianson, R., Danyluk, M.,...Wekerle, G. (2012). Could Toronto provide $10 \%$ of its fresh vegetable requirements from within its own boundaries? Part II, policy supports and program design. Journal of Agriculture, Food Systems, and Community Development, 2(2), 147-169. http://dx.doi.org/10.5304/jafscd.2012.022.002

Mannion, A. (2009). Green acres in the big city: Increase in urban agriculture leads to new ordinances. American City \& County, 124, 16. http://americancityandcounty.com/

Meener, M. R., \& Hoover, B. M. (2012). Community food security via urban agriculture: Understanding people, place, economy, and accessibility from a food justice perspective. Journal of Agriculture Food Systems, and Community Development, 3(1), 143-160. http://dx.doi.org/10.5304/jafscd.2012.031.013
Mendes, W., Balmer, K., Kaethler, T., \& Rhoads, A. (2008). Using land inventories to plan for urban agriculture: Experiences from Portland and Vancouver. Journal of the American Planning Association, 74(4), 435-449. http://dx.doi.org/10.1080/01944360802354923

Mirsch, L., \& Dimitri, C. (2012). Access to sustainably produced food: An investigation of organic food availability in Manhattan, New York. Journal of Agriculture, Food Systems, and Community Development, 2(3), 193-209.

http://dx.doi.org/10.5304/jafscd.2012.023.001

Mougeot, L. J. A. (2000). Urban agriculture: Definition, presence, potentials and risks. In N. Bakker, M. Dubbeling, S. Gundel, U. Sabel Koschella \& H. de Zeeuw (Eds.), Growing cities, growing food: Urban agriculture on the policy agenda (pp. 1-42). Ottawa, Canada: IDRC. http://hdl.handle.net/10625/7433

Mukherji, N., \& Morales, A. (2010). Zoning for urban agriculture. Zoning Practice, 3(10), 2-7.

Ojo, S. O. (2009). Backyard farming: A panacea for food security in Nigeria. Journal of Human Ecology, 28(2), 127-133. http://www.krepublishers.com/02Journals/JHE/JHE-00-0-000-000-1990-Web/JHE00-0-000-000-1990-1-Cover.htm

Patel, S., \& MacRae, R. (2012). Community supported agriculture in the city: The case of Toronto. Journal of Agriculture, Food Systems, and Community Development, 2(4), 85-100. http://dx.doi.org/10.5304/jafscd.2012.024.003

Smith, V. M. (2011). Growing our own: The socioeconomic value of community food production (Unpublished doctoral dissertation). University of Wisconsin, Madison, Wisconsin.

U.S. Census Bureau. (2009). American FactFinder.

Retrieved from http://factfinder2.census.gov/faces/nav/jsf/ pages/searchresults.xhtml?refresh $=\mathrm{t}$

U.S. Census Bureau. (2012). Census 2000 urban and rural classification. Retrieved from http://www.census.gov/geo/reference/ua/urbanrural-2000.html

U.S. Department of Agriculture [USDA], Agricultural Research Service. (n.d.). National Nutrient Database for Standard Reference (Release 26). Retrieved from http://ndb.nal.usda.gov/ndb/search/list\# 
USDA, Center for Nutrition Policy and Promotion. (n.d.). Official USD A food plans: Cost of food at home at four levels: U.S. average. Retrieved 2010 from http://www.cnpp.usda.gov/USDAFoodCostHome.htm

USDA, Center for Nutrition Policy and Promotion. (2005). MyPyramid food intake patterns. Alexandria, Virginia: USDA. Retrieved from http://www.choosemyplate.gov/food-groups/ downloads/MyPyramid Food Intake Patterns.pdf
Weissman, E. (2013). No buts about it...the value of urban food production: Response \#4 to Hallsworth and Wong's viewpoint, "Urban gardening: a valuable activity, but...". Journal of Agriculture, Food Systems, and Community Development, 3(2), 23-24. http://dx.doi.org/10.5304/jafscd.2013.032.014

Winne, M. (2008). Closing the food gap: Resetting the table in the land of plenty. Boston: Beacon Press. 